\title{
Influence of single-walled carbon nanotubes' diameter and length on the thermal conductivity of polymer composites
}

\author{
Zaw Ye Aung ${ }^{1, *}$, Pavel Prosuntsov ${ }^{1}$, and Sergey Reznik ${ }^{1}$ \\ ${ }^{1}$ Bauman Moscow State Technical University, 105005 5/1, 2-nd Baumanskaya Street, Russia
}

\begin{abstract}
Physical properties of composite materials can be improved by carbon nanotubes (CNTs). However, the thermal resistance between the polymer matrix and CNT at nanoscale can result in lower thermal conductivity. The paper analyses influence of CNTs' diameter and length on effective thermal conductivity in epoxy-based composites. It analyses the effect of the diameters, lengths and volumetric fraction of CNT on composites' thermal conductivity.
\end{abstract}

\section{Introduction}

Conventional polymer composite materials (PCM) have a relatively low thermal conductivity: $0.45 \mathrm{~W} /(\mathrm{m} \cdot \mathrm{K})$ for glass-fibre reinforced polymers, $0.25 \mathrm{~W} /(\mathrm{m} \cdot \mathrm{K})$ for organic fiber reinforced polymer, $0.8 \mathrm{~W} /(\mathrm{m} \cdot \mathrm{K})$ for carbon fiber reinforced polymer, which can result in large temperature changes, and lead to significant deformations. Carbon nanotubes (CNTs) are in high demand because of their unique electrical and mechanical properties. These properties are more likely to occur in single-walled CNTs (SWCNT), rather than in multilayer CNTs due to the latter's defect-free structure and low density $\left(1.33-1.40 \mathrm{~g} / \mathrm{cm}^{3}\right)$ [1-4].

A number of research works are devoted to theoretical and experimental methods of analyzing thermal conductivity of CNT-modified polymer composite materials. There are works that investigate properties and calculate optimum compositions of polypropylene (PP) and polyethylene (PE) based composites with 0.1-1 wt \% CNT filler. The analysis of the temperature dependences of the thermal conductivity of PP and PE with 0.1-0.5 wt \% CNT are presented in [5]. The components were compounded using the MEF-91.1 ultrasonic disperser. Thermophysical measurements were carried out using the IT-400 facility, which had undergone significant improvement. In the course of one short-term experiment, the temperature dependences of the thermal conductivity of solid materials could be determined through programmable time or temperature intervals using dynamic $\lambda$ calorimeter. It was established that the thermal conductivity of a PP-based, CNT-modified composite increases slightly: $\lambda=0.31-0.33 \mathrm{~W} /(\mathrm{m} \cdot \mathrm{K})$. Thermal conductivity of a PE-based, carbon-filled composite reaches $\lambda=0.4-0.42 \mathrm{~W} /(\mathrm{m} \cdot \mathrm{K})$.

\footnotetext{
* Corresponding author: hninmg18@gmail.com
} 
The Monte Carlo method was used in [6] to theoretically establish thermal conductivity of PE with single-walled CNTs. The volume fraction of SWCNTs constituted 0.006, 0.03, and 0.06 . The experiment used the laser ablation method to fabricate nanocomposites. Thermal conductivity of nanocomposites with 0.6 vt \% CNT estimated using the comparative method constituted $1.25 \mathrm{~W}(\mathrm{~m} \cdot \mathrm{K})$.

Thermal conductivity of single-walled nanotubes was measured experimentally and constituted $2000 \mathrm{~W} /(\mathrm{m} \cdot \mathrm{K})-10000 \mathrm{~W} /(\mathrm{m} \cdot \mathrm{K})$ [7-9]. Thermal conductivity of single-walled carbon nanotubes is markedly affected by their diameter and length. According to the experimental data, thermal conductivity of nanotubes $2.6 \mu \mathrm{m}$ in length and $1.7 \mathrm{~nm}$ in diameter is almost $3400 \mathrm{~W} /(\mathrm{m} \cdot \mathrm{K})$ at room temperature [10-12]. However, in practice, polymer composites very rarely demonstrate thermal conductivity that high.

New software packages, such as DIGIMAT-FE, open up opportunities for predicting the characteristics of nanomodified materials by taking various structural features into account. Apparently, it is of high importance to theoretically investigate the effect of the diameter and length of CNTs on the thermal conductivity of epoxy binders.

\section{Theoretical investigation of thermal conductivity prediction in nanomodified polymer composites}

The effect of the CNTs' diameter and length on the thermal conductivity coefficient was investigated for ten variants of CNT volume content from $0.1 \%$ to $1 \%$. Elastomers with less than $0.1 \mathrm{vt} \% \mathrm{CNT}$ were not considered, since it was found that small volume fractions of CNT do not improve the polymer's thermophysical characteristics. This being said, the low CNT content in the polymer during polymerization enables the cross-linking of macromolecules relative to the structural centers and increases toughness, bending and compression strength. More than 1 vt \% CNT will present technological difficulties to enable uniform distribution due to conglomeration and high surface activity

This paper considers the case of an epoxy binder with $0.25 \mathrm{~W} /(\mathrm{m} \cdot \mathrm{K})$ thermal conductivity containing uniformly distributed CNT with $1 \pm 2 \eta \mathrm{m}$ characteristic diameter and $100 \pm 500 \eta \mathrm{m}$ lengths.

DIGIMAT-FE module was used to build geometric models of a representative volume element of polymer composite. Simulation was performed with the parameters specified in Table 1. Fig. 1 and 2 show representative volume elements of the material with different CNT volume fractions created in DIGIMAT-FE module.

Table 1. Binder and nanotubes properties.

\begin{tabular}{|c|c|c|}
\hline Property & Epoxy binder & CNT \\
\hline Density, $\mathrm{kg} / \mathrm{m}^{3}$ & 2000 & 1400 \\
\hline Heat capacity, $\mathrm{J} / \mathrm{kg} \cdot \mathrm{K})$ & 700 & 800 \\
\hline Thermal conductivity, $\mathrm{W} /(\mathrm{m} \cdot \mathrm{K})$ & 0.25 & 2000 \\
\hline Volume fraction, $V_{l} / V$ & & $0.001-0.01$ \\
\hline Diameter $d=2 r, \eta m$ & & $1-2$ \\
\hline Length $l, \eta m$ & & $100-500$ \\
\hline
\end{tabular}




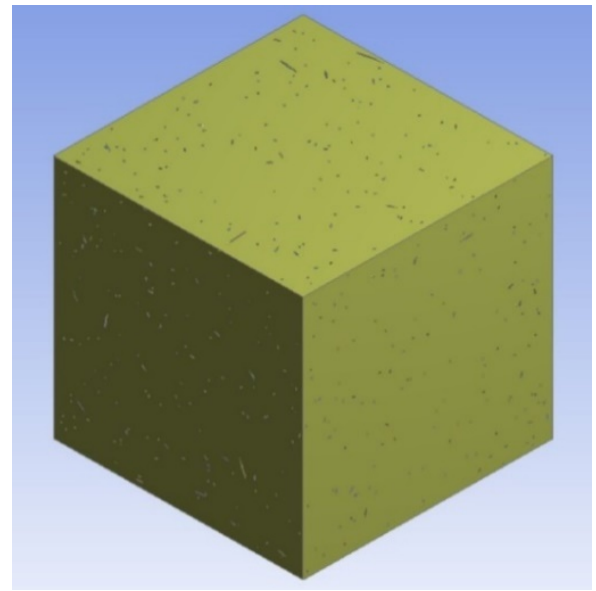

(a)

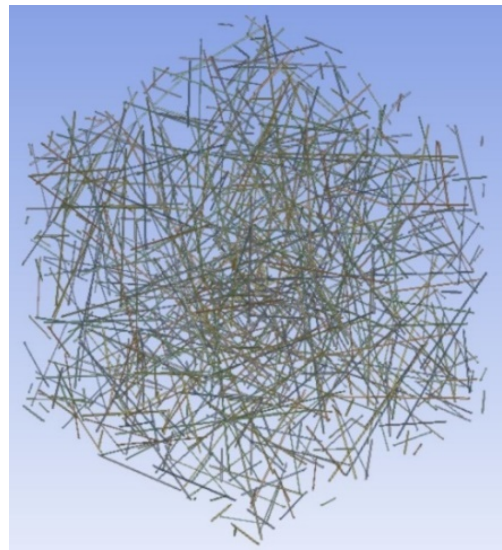

(b)

Fig. 1. Geometric model of a representative volume element of epoxy binder with 1 vt \% CNT (a); distribution of CNTs, $500 \eta \mathrm{m}$ length, 2 ๆm diameter (b)

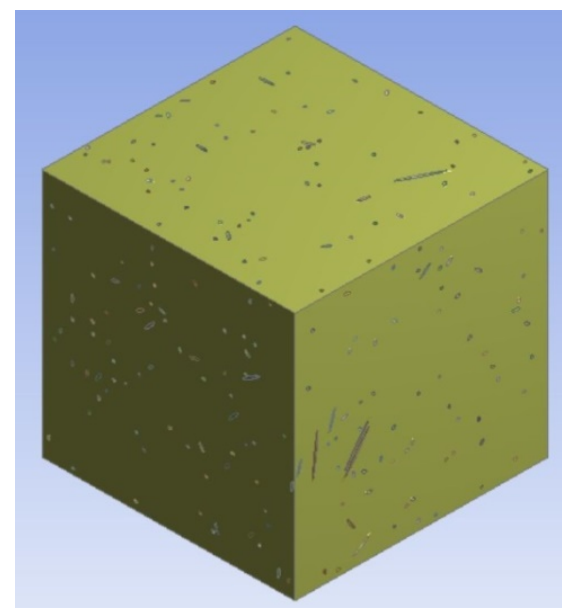

a)

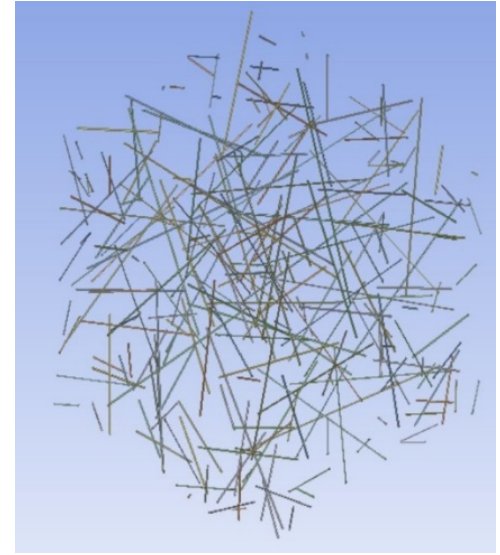

(b)

Fig. 2. Geometric model of a representative volume element of epoxy binder with $1 \%$ vt CNTs (a); distribution of CNTs, $100 \eta \mathrm{m}$ length, $1 \eta \mathrm{m}$ diameter (b)

The geometric models were used to create finite element models. After boundary conditions (thermal loads, symmetry conditions) had been applied, the finite element model were calculated using the ANSYS software. To model heat transfer in a volume element, $T_{\text {ш1 и }} T_{\text {ш2 }}$ temperatures were set for two of the surfaces, while the remaining surfaces were assumed to be insulated. Modelling estimated the heat flux through the sample. Fig. 3 shows temperature fields in the representative volume elements of PCM with CNT. 


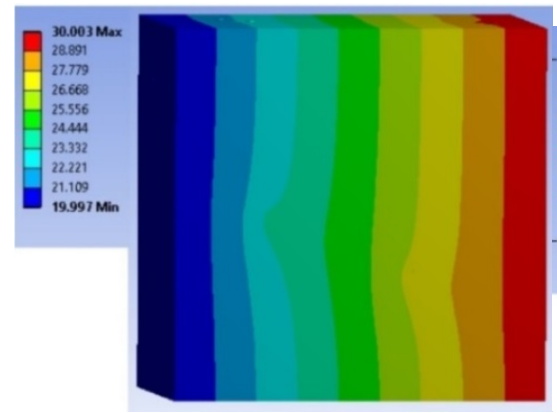

(a)

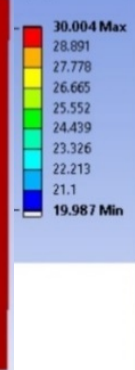

(1)

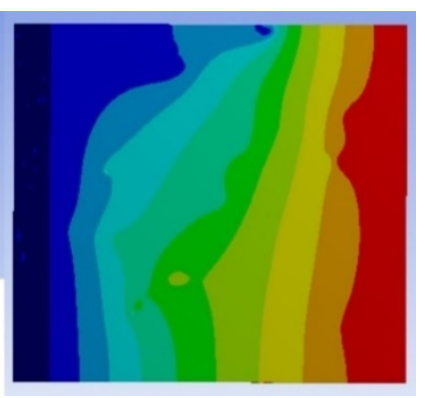

(b)

Fig. 3. Temperature distribution in the representative volume elements of epoxy binder with varying CNT volume fraction: a) $0.1 \mathrm{vt} \% \mathrm{CNT}$; b) $1.0 \mathrm{vt} \% \mathrm{CNT}$

\section{Calculation of coefficient of thermal conductivity}

This section presents the results of calculating thermal conductivity of PCM with varying CNTs' volume fraction, diameters and lengths. The thermal conductivity of nanotubes varied depending on the volume fraction $(0.1 \%$ to $1 \%)$. The effect of the CNT diameter (1 $2 \eta \mathrm{m})$ on the heat capacity, density, and thermal conductivity of PCM was estimated. It was found that the CNT diameter has little effect on the thermal conductivity. For example, for $1 \eta \mathrm{m}$ diameter and $1.0 \%$ volume fraction, thermal conductivity constituted $0.61 \mathrm{~W} /(\mathrm{m} \cdot \mathrm{K})$, and for $2 \eta \mathrm{m}$ diameter and the same volume fraction, thermal conductivity was 0.77 $\mathrm{W} /(\mathrm{m} \cdot \mathrm{K})$ (Fig. 4). Thermal conductivity of PCM was found to be more sensitive to the CNT length. For example, for $100 \eta \mathrm{m}$ length, $2 \eta \mathrm{m}$ diameter and a $1.0 \%$ volume fraction, thermal conductivity was $0.77 \mathrm{~W} /(\mathrm{m} \cdot \mathrm{K})$, while for $500 \eta \mathrm{m}$ length, the same diameter and the same volume fraction, thermal conductivity increased to $2.03 \mathrm{~W} /(\mathrm{m} \cdot \mathrm{K})$ (Fig. 5).

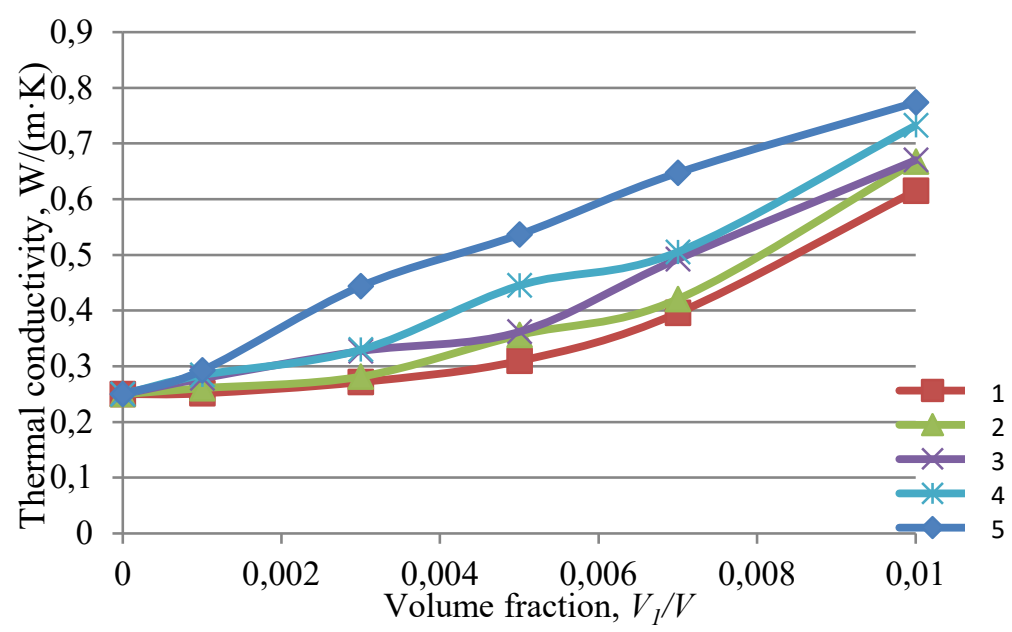

Fig. 4. Thermal conductivity of CNT-modified epoxy binder (CNT length $100 \mathrm{\eta m})$

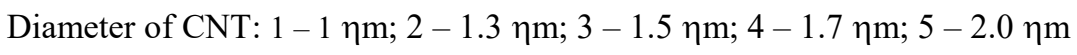




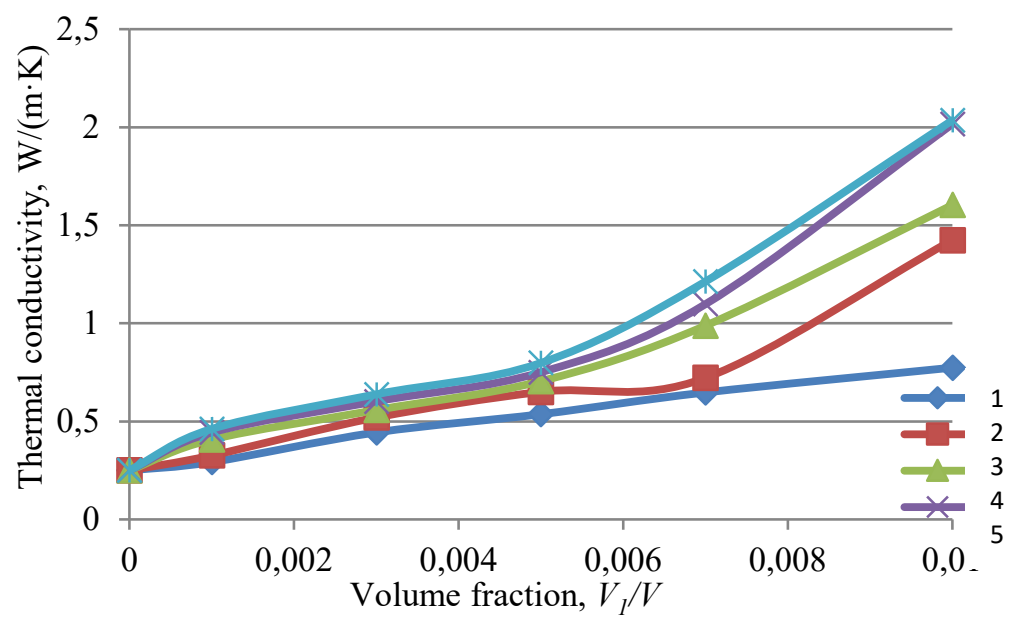

Fig. 5. Thermal conductivity of modified epoxy binder (CNT diameter $2 \eta \mathrm{m})$ depending on CNT length. Length of CNT: $1-100 \eta \mathrm{m} ; 2-200 \eta \mathrm{m} ; 3-300 \eta \mathrm{m} ; 4-400 \eta \mathrm{m} ; 5-500 \eta \mathrm{m}$

\section{Conclusion}

The results of the study showed that the coefficient of thermal conductivity of polymer nanocomposites based on epoxy resin using nanomodifiers in the form of CNTS is weakly dependent on their diameter. The study found that the coefficient of thermal conductivity increases with the length of CNT. The obtained results can be used as basic recommendations for developers of nanocomposites based on epoxy resin to choose the optimal values of CNT length to improve the thermal properties of materials.

\section{References}

1. P.M. Ajaya, Nanotubes from carbon, Chemical Reviews, 99, 7 (1999)

2. V.A. Shakhnov, et al, Journal of Physics: Conference Series 829(1), (2017)

3. C. Park, Z. Ounaies, et al, NASA/CR-2002-211940, ICASE Report. 36 (2002)

4. I.V. Bessonov, S.V. Reznik, et al, EPJ Web of Conferences 110, (2016)

5. A.V. Grishin, O.A. Medvedeva, O.N. Popov, Successes in Chemistry and Chemical Technology, 30, 10(179) (2016)

6. R. Haggenmueller, C. Guthy, J.R. Lukes et al, Thermal and electrical conductivity, Macromolecules, 40, 7 (2007)

7. C. H. Yu, L. Shi, Z. Yao, et al, Nano Lett, 5, 9 (2005)

8. V.S. Zarubin, E.S. Sergeeva, Journal of Physics: Conference Series 991(1), (2018)

9. O.S. Erkovich, P.A. Ivliev, Herald of the Bauman Moscow State Technical University, Series Natural Sciences 4, (2016)

10. E. Pop, D. Mann, Q. Wang, et al, Nano Lett, 6, 1 (2006)

11. J. R. Lukes., H. Zhong, J. of Heat Transfer, 129, 6 (2007)

12. E.S. Sergeeva, Herald of the Bauman Moscow State Technical University, Series Natural Sciences 2, (2018) 